\title{
Red cell distribution width as biomarker in older adults: a brief review
}

Keywords: red cell distribution width, biomarker, elderly, risk factors

\section{Abbreviations: RDW, red cell distribution width}

\section{Introduction}

For many years, clinical researchers have spent a lot of time and funding obtaining prognostic factors with a good predictive value for acute and chronic disorders. However, such markers are not available word wide, and its determination adds an extra cost to the patient and health institutions. ${ }^{1}$ Red blood cell distribution width (RDW) is a parameter of circulating erythrocytes measured by hematology analyzer. It is calculated automatically and it is expressed as a percentage. A normal RDW is 11.5 to $14.5 \%$. This parameter has been typically used in hematology to diagnose microcytic anemia. However current studies have shown that RDW played a key role in acute and chronic diseases through various potential physiological and pathological manifestations. ${ }^{2,3}$ In fact, in the last 10 years, clinical studies have shown strong statistical and independent associations between higher RDW and several diseases such as cardiovascular diseases, diabetes, cancer, pneumonia and gastrointestinal disorders, as well as other acute or chronic conditions, which in turn are present in older adults. ${ }^{4,5}$ As RDW is an inexpensive and routine biomarker, with high reproducibility and is widely available in all hematological analyzers, efforts to establish its clinical role could be very valuable for morbidity and mortality risk stratification in older adults.

\section{Discussion}

\section{RDW, morbidity and mortality in older adults}

RDW has been historically useful to diagnose anemia-related disorders such as iron, folate and vitamin B12 deficiencies, sickle cell- $\beta$-thalassemia and immune hemolytic anemia. ${ }^{6,7}$ For many years, the RDW was only considered useful for hematological diseases. However, Felker et al. in an elegant paper, demonstrated a close relationship between increased RDW and poor prognosis in patients with cardiovascular diseases, irrespective of their anemia status. ${ }^{8}$ Subsequently, this biomarker began to be explored more deeply in various cardiovascular diseases such as acute or chronic heart failure, acute myocardial infarction, atrial fibrillation, among others. These studies reported a high predictive value related to cardiovascular morbidity and mortality. ${ }^{9-11}$ More interestingly, several reports expanded this notion by assessing the relationship of RDW with other acute or chronic diseases, such as diabetes, cancer, kidney diseases, liver failure and other pathologies, as shown in Figure 1. For example, the use of the RDW in the diagnosis of malignant tumors (i.e. endometrial, lung, colon and liver cancers) has recently attracted much attention. ${ }^{12} \mathrm{~A}$ high RDW has been positively correlated with the stage of several cancers, including the number of metastatic tissues, tumor diameter, and over expression of established cancer biomarkers. ${ }^{12}$ Likewise, current reports have showed higher RDW levels in patients with neurological or psychiatric disorders such as migraine, depression and anxiety. ${ }^{13,14}$
Volume 2 Issue 3 - 2017

\author{
Hernán Alcaíno,' Mario Chiong, ${ }^{2}$ David \\ Reyes,' Humberto Toledo',3 \\ 'Centro Multidiciplinario de Investigación en Salud del Valle de \\ Aconcagua, Universidad de Valparaiso, Chile \\ ${ }^{2}$ Advanced Center for Chronic Disease, Universidad de Chile, \\ Chile \\ ${ }^{3}$ Servicio de Cardiología, Hospital San Camilo, Chile
}

Correspondence: Hernán Alcaíno, Facultad de Medicina, Universidad de Valparaíso, Campus San Felipe, San Felipe, Chile, Tel +56944253 I6, Email hernan.alcainoo@uv.cl

Received: August 29, 2017| Published: October 09, 2017

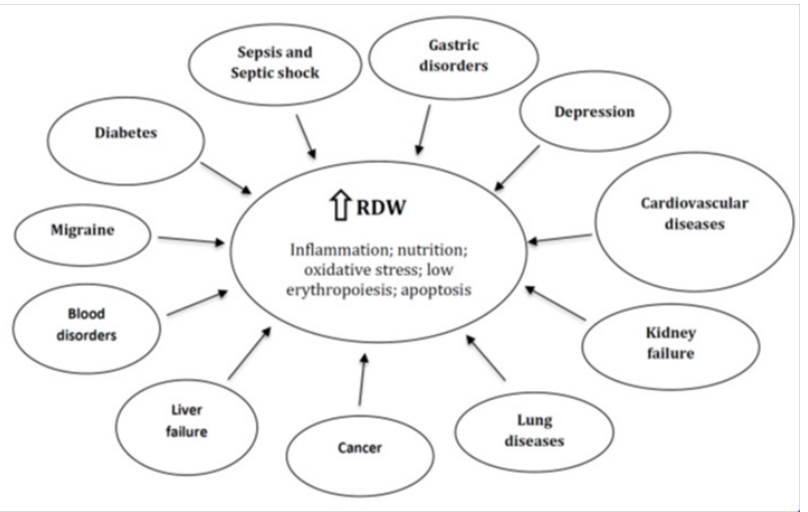

Figure I Acute or chronic diseases related with RDW in the elderly. Potential mechanisms involved in the increase of RDW. The relationship between cardiovascular diseases and RDW has been highly studied and reported in medical literature

\section{An important question: how does the rdw increase?}

Although different studies have demonstrated that RDW is a robust and independent predictor of morbidity and mortality compared with another established risk biomarkers, the mechanism explaining why a high RDW value is associated with acute or chronic diseases remains unknown. It has been proposed that inflammation and oxidative stress are the main events that could alter erythrocyte homeostasis and therefore to induce a RDW increase. ${ }^{2,3}$ In this regard, inflammation inhibits bone marrow function and iron metabolism. ${ }^{2,3,16}$ Moreover, proinflammatory cytokines inhibits erythropoietininduced erythrocyte maturation and proliferation, which is reflected partly by a RDW increase. ${ }^{15}$ Lippi et al., reported that the RDW was positively correlated with the erythrocyte sedimentation rate and high-sensitivity $\mathrm{C}$-reactive protein level, indicating that the RDW reflects the inflammatory state of the body. ${ }^{16}$ In addition, metabolic abnormalities such as shortening of telomere length, poor nutritional status (deficiencies of iron, folic acid, and vitamin B12), dyslipidemia, hypertension, erythrocyte death or alteration of erythropoietin function might contribute to RDW increase. ${ }^{17,18}$ All these alterations 
are common in older people; thus, we could hypothesize that RDW is a "master" blood biomarker reflecting the general health status in the elderly.

\section{Conclusion}

Considering the economic, technical and clinical advantages, the measurement of RDW alone or combined with other stablished clinical biomarkers could be very useful for improving the risk stratification of morbidity and mortality of many diseases. However unraveling the detailed mechanisms associated with higher levels of RDW is necessary for the future acceptance of this parameter within the medical and scientific community as a general and useful marker.

\section{Acknowledgements}

None.

\section{Conflict of interest}

The authors declare no conflict of interest.

\section{References}

1. Barron E, Lara J, White M, et al. Blood-borne biomarkers of mortality risk: systematic review of cohort studies. PLoS One. 2015;10(6):e0127550.

2. Danese E, Lippi G, Montagnana M. Red blood cell distribution width and cardiovascular diseases. J Thorac Dis. 2015;7(10):E402-E411.

3. Alcaino H, Pozo J, Pavez M, et al. Red cell distribution width as a risk marker in patients with cardiovascular diseases. Rev Med Chil. 2016;144(5):634-642.

4. Shao Q, Li L, Li G, et al. Prognostic value of red blood cell distribution width in heart failure patients: a meta-analysis. Int $J$ Cardiol. 2015;179:495-499.

5. Salvagno GL, Sanchis GF, Picanza A, et al. Red blood cell distribution width: A simple parameter with multiple clinical applications. Crit Rev Clin Lab Sci. 2015;52(2):86-105.

6. Farley PC, Foland J. Iron deficiency anemia. How to diagnose and correct. Postgrad Med. 1990;87(2):89-93.
7. Chatthanawaree W. Biomarkers of cobalamin (vitamin B12) deficiency and its application. J Nutr Health Aging. 2011;15(3):227-231.

8. Felker GM, Allen LA, Pocock SJ, et al. Red cell distribution width as a novel prognostic marker in heart failure: data from the CHARM Program and the Duke Databank. J Am Coll Cardiol. 2007;50(1):40-47.

9. Dai Y, Konishi H, Takagi A, et al. Red cell distribution width predicts short- and long-term outcomes of acute congestive heart failure more effectively than hemoglobin. Exp Ther Med. 2014;8(2):600-606.

10. Akin F, Köse N, Ayça B, et al. Relation between red cell distribution width and severity of coronary artery disease in patients with acute myocardial infarction. Angiology. 2013;64(8):592-596.

11. Ertaş G, Aydin C, Sönmez O, et al. Red cell distribution width predicts new-onset atrial fibrillation after coronary artery bypass grafting. Scand Cardiovasc J. 2013;47(3):132-135.

12. Montagnana M, Danese E. Red cell distribution width and cancer. Ann Transl Med. 2016;4(20):399-410.

13. Lippi G, Cervellin G, Mattiuzzi C. Migraine and erythrocyte biology: a review. Int J Lab Hematol. 2014;36(6):591-597.

14. Shafiee M, Tayefi M, Hassanian SM, et al. Depression and anxiety symptoms are associated with white blood cell count and red cell distribution width: A sex-stratified analysis in a population-based study. Psychoneuroendocrinology. 2017;84:101-108.

15. Gyawali P, Richards RS, Bwititi PT, et al. Association of abnormal erythrocyte morphology with oxidative stress and inflammation in metabolic syndrome. Blood Cells Mol Dis. 2015;54(4):360-363.

16. Lippi G, Targher G, Montagnana M, et al. Relation between red blood cell distribution width and inflammatory biomarkers in a large cohort of unselected outpatients. Arch Pathol Lab Med. 2009;133(4):628-632.

17. Triantafyllidi H, Palaiodimos L, Ikonomidis I, et al. The independent association of two priceless parameters: Pulse pressure and red cell distribution width in recently diagnosed hypertensive patients. Hellenic $J$ Cardiol. 2016;57(6):459-462.

18. Lippi G, Sanchis-Gomar F, Danese E, et al. Association of red blood cell distribution width with plasma lipids in a general population of unselected outpatients. Kardiol Pol. 2013;71(9):931-936. 